\title{
INFANCIA Y LECTURA
}

\author{
Amanda Céspedes
}




\section{AMANDA CÉSPEDES}

Médico cirujano de la Universidad de Chile. Psiquiatra infanto-juvenil de la Universidad de Chile. Postgrado en Neuropsicología y Neuropsiquiatría InfantoJuvenil, Università Degli Studi de Turín, Italia. Ex académica de la Pontificia Universidad Católica de Chile. Directora del Instituto de Neurociencias aplicadas a la educación y salud mental del niño. Miembro Honorario del Colegio de Psicólogos del Perú y de la Sociedad de Dislexia del Uruguay. Es también una reconocida escritora. 


\section{INFANCIA Y LECTURA}

Mis especiales agradecimientos a Gloria Silva Montes por su generoso encender en mí la pasión por el cerebro lector.

“Es exagerado pensar que nuestras vidas dependen en alguna medida de nuestras lecturas? ¿Que el destino de nuestras horas está ligado a los textos que fueron conformando en nosotros una visión del mundo en un arco que se traza entre el desasosiego y el entusiasmo?".

"Leer para ponerse de pie y modificar el espesor de los días". Ángela Pradelli

Estas bellas y lúcidas palabras de Ángela Pradelli (Pradelli, 2013) podrían adquirir una súbita opacidad de obsolescencia frente a la explosión de tecnologías digitales que nos invitan a nuevos modos de conocer, porque, sin que la Pradelli lo diga explícitamente, ella parece sugerir que el destino de nuestras horas está ligado a esos libros que alimentaron nuestras cosmovisiones, anhelos y secretas ensoñaciones. ¿Seguirán siendo los libros, con el sutil fru fru de sus hojas y con su desvaído olor a imprenta o a estantería, los que encantarán a quienes hoy son apenas bebés, naciendo en y para una nueva era, y les invitarán a esconderse en un desván para leer hasta embriagarse de pasión?

Leer es una alquimia sorprendente, diseñada por la evolución para cristalizar en forma natural poco después del primer lustro de vida y, desde ese momento en adelante, "poner de pie" al lector y permitirle crecer sin límite. Ese crecimiento interno se denomina alfabetización. Si bien podemos aprender a leer cuando adultos, lo natural es la cristalización temprana de la lectura, un estallido de luz que llega poco después del primer lustro de vida para iluminar el tránsito de los niños por la escuela y por la vida.

¿Cómo ocurre esta alquimia tan específicamente humana? ¿Qué ingredientes le dan vida? Lo habitual es creer que esos ingredientes son las letras, esos dibujos sutiles sobre un papel que se van encadenando para dar nacimiento a la palabra escrita, y los sonidos que se corresponden con cada grafema. Esta creencia es la que impulsa a quienes acompañan a los niños en su desarrollo a forzarles cada vez más tempranamente a identificar esos caprichosos dibujos y darles categoría de letras o grafemas, en la creencia de que, una vez que ese niño o niña "se largue a leer", habrá culminado el esfuerzo por alfabetizarle. Sin embargo, el descubrimiento por parte del niño/a de la asociación fonemagrafema no es ni inicio ni culminación: es tan solo la primera - y asombrosa - manifestación visible de un fenómeno misterioso que venía gestándose desde el nacimiento, y que irá creciendo a partir de ese momento sin más límites que el anhelo de conocer. A partir del aprender a leer, la lectura será un fenómeno de transmigración, de expansión ilimitada, un viaje del cual regresamos transformados, distintos a como éramos; siendo un proceso permanente, la transformación que experimentamos es igualmente constante, jamás concluye. Esta capacidad de transportar al lector hacia ámbitos lejanos sin más 
combustibles que la emoción, la imaginación y el bagaje cognitivo interno es la asombrosa propiedad generativa de la lectura que, a su vez, refleja a cabalidad la igualmente prodigiosa capacidad generativa del cerebro humano.

\section{LECTURA Y CEREBRO INFANTIL}

"Un viento un fuego para abrir la noche una memoria un modo de vencer al olvido". Juan Gelman

El cerebro infantil está en una activa maduración sin receso ni pausa; ello significa que se encuentra en un permanente proceso de transformación. En los genes están codificadas las instrucciones para construir un cableado neuronal que será el soporte para la creación de redes neuronales dinámicas a partir de las experiencias que el niño irá viviendo. El cableado neuronal de soporte no es fijo; por el contrario, cada cierto tiempo experimenta cambios, los que tienen la propiedad de ser anticipatorios: preparan al cerebro para que esté máximamente receptivo a lo que vendrá. En otras palabras, cada cierto tiempo el cerebro infantil se reorganiza a sí mismo, respondiendo a instrucciones que la evolución ha ido escribiendo pacientemente en el ADN. Que el cerebro infantil posea un cableado neuronal de soporte, ávido de experiencias enriquecedoras, significa que todos los actores sociales tenemos una abrumadora responsabilidad: cada niño y niña viene al mundo portando un espléndido potencial cognitivo, esperando recibir las mejores experiencias y oportunidades para enriquecer de modo ilimitado ese soporte asombroso, herencia de la evolución, y de este modo alcanzar la cima del desarrollo humano. En consecuencia, alfabetizarse es un derecho fundamental de la infancia, porque está en la naturaleza humana acceder al mundo y crecer ilimitadamente a través de la palabra escrita.

El primer cableado neuronal de soporte, y su respectivo enriquecimiento desde las experiencias y oportunidades, ocurre desde el tercer trimestre intrauterino y se extiende por los primeros 5 años de la vida, aportando funciones y habilidades esenciales que permitirán el ingreso gradual a la lectura y los procesos de alfabetización. En otras palabras, el cerebro infantil se dispone para la lectura desde antes de nacer. Las funciones y habilidades cerebrales protagónicas en esta etapa son la refinada capacidad perceptiva del niño, la veloz emergencia del lenguaje verbal y un procesamiento holístico de la información que ingresa al cerebro, permitiendo el surgimiento de una mente prodigiosamente imaginativa, libre, fantasiosa, que transforma constantemente la realidad objetiva a través del juego y del contacto directo con la experiencia. El cerebro durante la primera infancia posee el triple de neuronas que en edades posteriores y, por lo tanto, tres veces más potencialidad sináptica; ellas están localizadas en su mayoría en el hemisferio derecho. Este cerebro prodigioso es la base de una mente ávida de conocer a través de percibir, igualmente ávida de crear y transformar a través del conocer. Desde la lectura de cuentos, del juego, de las conversaciones con adultos sensibles a la fantasía inagotable de esa mente infantil, y de la riqueza de material escrito que le rodea, el niño 
va preparando su mente para lo que ha de venir: el lenguaje escrito. Es una semilla que va germinando, agradecida del agua y los nutrientes de la tierra donde ha sido plantada. Todavía no hay brote, pero un activo proceso de germinación está ocurriendo. Y, del mismo modo que una planta no germina si no participa el gesto supremo del amor a través del riego delicado, la potencialidad sináptica del cerebro del párvulo se actualiza activamente cuando se asoma al asombroso mundo de los relatos contados por quien le ama. La imaginación, la fantasía y la activa construcción del léxico, la sintaxis y la semántica requieren para fertilizar de la calidez de una certeza: saberse amado. Los adultos tenemos la responsabilidad de proporcionar al párvulo todas las experiencias familiares y comunitarias que estimulan, fomentan y facilitan tanto el correcto desarrollo del lenguaje oral como la emergencia temprana de la lectura y su igualmente temprana cristalización (P. Kuhl, 2011). Leer tempranamente exige que el niño haya vivido ricas experiencias lingüísticas desde muy pequeño en situaciones rutinarias (baño, comida, juegos, paseos) y en formatos precisos; ambos factores permiten la construcción de guiones en los cuales las acciones están estructuradas causal, espacial y temporalmente, favoreciendo la emergencia de las primeras narrativas. Leer tempranamente exige que el niño pequeño haya crecido en un entorno rico en material impreso, junto a adultos y hermanos mayores implicados en interacciones dinámicas con dicho material impreso y, muy especialmente, participativos en la lectura de cuentos. Adultos y hermanos mayores dispuestos a responder sus preguntas acerca de las ilustraciones de los libros, las palabras que acompañan a las ilustraciones, las etiquetas de los envases, la propaganda escrita en revistas de moda, las listas de supermercado, las cuentas de luz y agua, etc. La lectura de cuentos es, probablemente, la instancia que más estimula la curiosidad del párvulo por el material impreso y su deseo de dominar una competencia misteriosa: descifrar esos símbolos que representan palabras. Los cuentos apuntan directamente al interés, la emoción y la curiosidad infantil; de allí que sea universal el deseo compulsivo de escuchar una y otra vez el mismo cuento y "hacer como que están leyendo". A medida que se lee repetidamente el cuento, el niño transita desde un interés primario por las ilustraciones a focalizarse interesadamente en las palabras, los conceptos, las construcciones gramaticales, hasta llegar a un relato coherente y lingüísticamente rico del cuento por parte del niño, en la medida que el adulto permita y fomente las intervenciones activas del niño durante la lectura (adulto mediador de la lectura emergente). Es el momento en que nace la estructura narrativa en un párvulo, potente índice de alfabetización exitosa al ingresar a la escuela (Borzone de Manrique, 2009). Una estructura narrativa temprana es uno de los índices de lectura temprana más confiables en la edad preescolar. Finalmente, leer tempranamente exige ser intensamente amado.

Entre los 5 y los 7 años de vida, el cerebro experimenta un ajuste del cableado básico de soporte, especialmente a nivel del cerebelo y el hemisferio izquierdo. Si el enriquecimiento cognitivo y afectivo durante los años previos ha sido adecuado, una activa mielinización entre ambos hemisferios cerebrales y entre cerebro y cerebelo, además de nuevas conexiones al interior de la corteza del hemisferio izquierdo, permitirán un mayor refinamiento de las funciones de secuenciación, simbolización y abstracción. Este es un momento portentoso, que podemos equiparar a la aparición del brote, la plántula, 
sobre la superficie de la tierra. El niño descubre que una palabra es una secuencia dinámica y flexible de sonidos, los cuales pueden ser manipulados — sacar sonidos, agregar sonidos, cambiar de posición un sonido en la palabra - para formar nuevas secuencias y dar origen a nuevas palabras. Descubre que puede romper la secuencia, introduciendo nuevos sonidos que crean divertidas sonoridades. Su primer descubrimiento es que los sonidos se hermanan formando sílabas, pero muy pronto comprueba que también suenan de modo aislado. Son los fonemas. El paso siguiente es un salto hacia otro lenguaje nuevo, del cual ya conocía su existencia pero no sabía descifrarlo: descubre que esos caprichosos dibujos cuyos nombres debió aprender a identificar, son en realidad símbolos que representan los sonidos constituyentes de la palabra: los grafemas. El paso final es lograr articularlos en secuencias que darán origen a palabras. Ha cristalizado la lectura y ahora el niño es dueño de un nuevo patrimonio: el lenguaje escrito ya no es un misterio, es una realidad. Una llave que le irá abriendo infinitas puertas al conocimiento, un pasaje que le permitirá embarcarse todas las veces que desee en un viaje sin tiempo y sin fronteras a bordo de una nave misteriosa, el material escrito. Su cerebro ya no es el mismo: merced a la sinergia entre maduración biológica —ese cableado básico de soporte- y la entrega de múltiples y enriquecedoras experiencias ambientales, se ha producido una modificación morfológica de amplias regiones cerebrales: extensas conexiones a nivel de las encrucijadas témporo-parieto-occipitales, corteza frontal y un engrosamiento significativo del cuerpo calloso a nivel del esplenio. La corteza occipital se ha especializado en la detección de los sutiles rasgos distintivos de una letra, esté ella escrita en forma minúscula o mayúscula, imprenta o manuscrita; a partir de este ejercicio perceptivo, su cerebro irá creando patrones invariables. Por la misma época, la corteza temporal discriminará la unidad fonológica extrayéndola del flujo de habla continua, y sus conexiones con la corteza occipital le permitirán asociarla con la letra correspondiente. La memoria ha de trabajar activamente en el reconocimiento y recuperación de patrones auditivos y visuales específicos. Este cerebro nuevo es el portentoso recurso epigenético humano para participar activamente en la construcción de la cultura.

Han bastado siete años para adueñarse de una conquista arduamente perseguida a través de la evolución. Como plantea Maryanne Wolff, es muy probable que la civilización occidental haya acelerado su progreso a partir de un cambio de código; desde los signos logográficos propios de la escritura jeroglífica egipcia (a menudo dispuesta en bustrofedon: un renglón escrito de izquierda a derecha y el siguiente de derecha a izquierda, "a la manera del buey que ara"), el código maya, el código inca y el chino, entre muchos otros, la aparición del código alfabético griego garantiza una lectura eficaz gracias a la economía de caracteres (unos 26 en comparación con varios miles en el código egipcio), permitiendo dedicar parte significativa de las regiones cerebrales involucradas en la lectura a conquistar fluidez (M. Wolf, 2008). En otras palabras, a los griegos debemos el nacimiento de un cerebro lector a edades tempranas, lo cual amplía de modo ilimitado el ingreso a la fase siguiente, al vértigo de una metamorfosis creativa destinada a cambiar el destino de ese pequeño lector: la aventura de leer para comprender y aprehender el mundo. 
Por la época en la que el niño se inicia en el descifrado de un código escrito, su bagaje lingüístico ha experimentado cambios notables que contribuyen al enriquecimiento cognitivo. Estos cambios se iniciaron varios años antes, impulsados por el cálido viento de las emociones, en especial de la inagotable curiosidad y de la igualmente inagotable imaginación del párvulo. Uno de estos logros es el conocimiento del lenguaje literario, cuyos rasgos léxicos, sintácticos y semánticos son absolutamente propios, originales y ajenos al lenguaje oral, cualidad que lo hace ser un factor de enriquecimiento cognitivo invaluable. Es un lenguaje florido, abundante en sustantivos novedosos, una rica enjundia de adjetivos calificativos, giros sintácticos tan desafiantes como un complicado paso de baile, analogías, metáforas... Este lenguaje literario, que llena de curiosidad y gozo al párvulo, prepara a la mente cognitiva para el salto mortal que implica comprender los textos escritos, un ejercicio arduo con propiedades generativas que se extenderá por toda la vida. Mucho antes de ingresar a la escuela, el párvulo va creando modelos lingüísticos internos que le ayudarán más tarde a ingresar al mundo de los textos, aportando los necesarios contextos. De este modo, se comienza a gestar una nueva categoría de lector, que irá naciendo gradualmente antes de que finalice la niñez: el lector experto. Este lector se enfrenta a una explosión de mensajes, códigos, significados sin titubear; con decisión y coraje se sumerge en las lecturas para emerger nuevo, transformado. Su condición de experto no es estática; por el contrario, a medida que lee más y más, la metamorfosis continúa en una inimaginable expansión.

Adquirir la categoría de lector experto comienza cuando se cae en la red seductora de la lectura por placer. Como suele coincidir su inicio con el comienzo de la escolarización, el niño candidato a lector experto es acechado por un enemigo falaz: la lectura obligatoria. Esos libros impuestos a la fuerza, que jamás se leerán bajo la anémica luz de una lamparita de velador eludiendo la perentoria orden de dormir o en el alféizar de una ventana, el hueco de la escalera, el duro banco de un parque o al interior de una somnolienta biblioteca pública. Serán libros a medio leer, el rostro contraído en un mohín de tedio, sin pasión, mecánicamente, escamoteando a disgusto un breve tiempo al juego en la plaza o a las hipnóticas pantallas digitales. Por el contrario, la lectura por placer se busca con avidez de adicto porque reivindica en los niños su derecho a la libertad. Nada más íntimo que ese diálogo en silencio con otros mundos agazapados en las páginas de un libro y nada más libertario que soñar en consonancia. Llegar a la categoría de lector experto exige al niño la confluencia de diversos factores; desde lo biológico, se precisa un cerebro que comenzó a ser prelector al menos 2000 días antes de llegar a la escuela primaria, el cual posee una arquitectura única y privativa de su condición de cerebro inicialmente alfabetizado. En lo psicológico, una mente tempranamente reflexiva, inclinada a lo imaginativo, con predilección por los mundos que parecen existir más allá de la experiencia inmediata y con facilidad para el procesamiento multidimensional, que consiste en la creación simultánea de imágenes, conceptos, analogías, metáforas; capaz de desarmar la información por partes e integrarla de modo global, convergiendo y divergiendo sin dificultad. En cuanto a lo ambiental, los lectores expertos tempranos suelen habitar casas donde escasean los aparatos de televisión pero abundan las estanterías repletas de libros, donde reina soberano el silencio apenas roto por el canto de los 
pájaros y no faltan los rincones soleados donde refugiarse llevando "un buen libro". En esas casas habitan adultos lectores y que también saben charlar de modo descontextualizado, es decir, rompiendo las fronteras de lo inmediato (los noticieros, la farándula) para volar a mundos lejanos en lo geográfico, lo temporal y lo realista. Son adultos que invitan a los niños a indagar, a atreverse a aportar a la charla sin temor a decir "una tontería" y que todavía recurren a los libros para encontrar respuestas que otros buscan con prisa en Google o Wikipedia.

Los lectores expertos se construyen a sí mismos, empleando una técnica que amenaza con la obsolescencia: leer. Y utilizan, para ello, materiales que se agrupan en una sola categoría: libros. A través de la práctica de leer apasionadamente, van ingresando a la elaboración de significados cada vez más complejos, enfatizando y aprehendiendo sus relaciones, desarchivando memorias y aportando su imaginación y conocimiento de mundo. Su cerebro desarrolla y emplea estrategias que son inicialmente cognitivas para pasar, más temprano que tarde, al nivel metacognitivo. En la etapa inicial de la experticia lectora o etapa de estrategias cognitivas, llamada "etapa de lector estratégico", los niños se esfuerzan en construir un almacén semántico amplio, contextos diversos, dominio de etimologías, etc. Su cerebro aparece intensamente activo en ambos hemisferios y en extensas zonas corticales, especialmente a nivel prefrontal. Un cerebro intensamente activo es un cerebro hacendoso, a la manera de un albañil preparando la fragua para luego construir el muro. Inevitablemente, la tarea le consumirá tiempo y sin duda que se agotará físicamente. Las lecturas elegidas le ayudarán a resistir la fatiga: ingredientes como la magia, la epopeya, el heroísmo, la oposición entre el bien y la maldad y alguna dosis de romance son como el vino en cantidad adecuada: ayudan a continuar la lectura en un suave estado de embriaguez. Los buenos escritores de literatura infantil conocen el poder de las emociones sabiamente dosificadas para cautivar y capturar a su público. El lector experto temprano se empodera al ingresar a una dimensión motivacional nueva: la lectura adquiere para él o ella un valor intrínseco (U. Schieffele, 2012), desarrollando una motivación igualmente intrínseca en términos de leer y aprender. Incrementa su autoconcepto como sujeto lector, adquiere una ortografía impecable y cada día aumenta su involucramiento afectivo con la lectura, entre otros factores de empoderamiento integral.

Por la época en que el niño agrega un cero a sus años contados en unidades, y dependiendo de la fuerza con la cual ha ido construyendo su calidad de "lector estratégico", el cerebro experimenta una nueva transformación del cableado neuronal de soporte. Es una nueva expresión del regalo que nos ha dado la evolución. Durante unos dos años aproximadamente, se pone en marcha en la corteza cerebral una activa eliminación de sinapsis seguida de una conectividad menos profusa, pero más eficiente y de una generosa mielinización, especialmente activa en el cuerpo calloso - que conecta ambos hemisferios cerebrales- y en los tractos que conectan cerebelo y corteza cerebral en vías de doble sentido. El resultado de esta remodelación arquitectónica cerebral es la aparición de una mente extraordinariamente sofisticada, metacognitiva, que dará nuevas e impensadas alas a la metamorfosis lectora. Es el nacimiento de un lector experto que abandona las estrategias conscientes para leer sin esfuerzo alguno, ingresando 
sin percibirlo al mundo infinito de los significados, los conceptos, las metáforas, las inferencias, generando hipótesis, contrastándolas e integrándolas, poniendo en ello un conocimiento de mundo cada vez más rico y más amplio. Un océano cognitivo cuyas medidas son la profundidad y la extensión infinitas. Las imágenes cerebrales de un lector experto menor de 20 años muestran cómo se van labrando nuevas rutas sinápticas, extraordinariamente concentradas y veloces. Módulos neuronales hemisféricos izquierdos muestran una reducción en la extensión de su conectividad, mientras que los módulos del hemisferio derecho y cerebelo derecho se expanden, mostrando tanto la arquitectura de la eficiencia cognitiva como el soporte esencial de la imaginación y las emociones en el fluido acceso a los significados del texto. El lector experto ha vencido al tiempo y a la fatiga y se yergue, triunfante, enarbolando su destreza lectora como el arma para conquistar todos los espacios sociales, históricos, culturales, intelectuales del mundo externo y el espacio infinito de su interioridad en un proceso de transformación generativa sin límites. A partir de este momento, es y será lo que ha leído y lo que continuará leyendo. La historia de un lector experto jamás acaba.

\section{LECTURA Y CIRCUNSTANCIA VITAL}

"...Como una corta fábula su cuerpo de vencido" Gabriela Mistral

El conocimiento de la biología cerebral al servicio de la lectura se transforma en una ironía amarga ante el tamaño de quienes continúan siendo los desheredados más vulnerables: los niños pobres. Resulta doloroso tener conciencia de la importancia de la lectura como fuerza generativa, transformadora y de empoderamiento del ser humano como sujeto social y, al mismo tiempo, constatar que los gobiernos han fracasado en la lucha contra la pobreza y su cohorte de flagelos: exclusión, privación y vulneración de derechos, entre ellos, el derecho a una adecuada alfabetización. Un niño pobre nace con un cerebro con potencialidades prodigiosas, pero cada año de vida en la pobreza irá cercenando su pleno potencial, impidiéndole participar plenamente y en pie de igualdad en la sociedad. Garantizar los servicios de salud y nutrición no es suficiente; tampoco lo es garantizar la cobertura y la conclusión de los estudios en educación inicial, primaria y secundaria. Es preciso repensar una educación preescolar y escolar de calidad en términos de equidad, y es urgente promover una mayor preparación de los docentes, especialmente en educación inicial, reformulando de modo igualmente urgente el concepto de alfabetización y de pertinencia cultural, además de promover en los maestros de niños y adolescentes el placer de la lectura, hoy abandonado por el placer de la televisión. Y es igualmente urgente ampliar el concepto de alfabetización, magramente reducido a una misión escolarizante, privativa de la escuela, para llevarlo al plano de una sociedad toda que alfabetiza, lo cual exige saber crear espacios estimulantes en las ciudades y barrios, promover el silencio atacando sin escrúpulos la algarabía hueca que emerge de parlantes en centros comerciales, patios de comida, parques y al interior mismo de 
los hogares; fortalecer la alfabetización al interior de las familias y de las comunidades rurales; promover ferias de libros infantiles de calidad, más bibliotecas públicas, bibliobuses, etc. Quizá sea utópico soñar un país de lectores expertos antes de los 15 años de edad, pero las utopías son posibles en la fragua de las voluntades.

El concepto de pobreza e infancia tiene connotaciones propias y específicas (revista Desafíos, 2010). Se construye sobre el principio de acceso a derechos económicos, sociales y culturales, entre los cuales el acceso a una correcta alfabetización es un derecho fundamental. Como hemos visto en los párrafos anteriores, la neurobiología de la lectura es enfática en mostrar que se comienza a leer antes de nacer; que la meta es lograr lectores expertos alrededor de los 10 años de edad; que la lectura transforma el cerebro del mismo modo como transformó la civilización en el devenir histórico humano y; finalmente, que la lectura transforma al niño, haciéndolo más profundamente humano, estableciendo un puente entre su interioridad y el mundo. Pero alfabetizar a los niños exige trabajar de manera sinérgica, coordinada e intersectorial, abordando dicha tarea desde la responsabilidad social y de políticas públicas del Estado y de la sociedad civil. Para ello, es preciso crear conciencia de lo urgente de la tarea. Dicha conciencia se inicia en las cifras y continúa con un necesario cambio de mirada, por cuanto las estadísticas no bastan. Las cifras son contundentes: uno de cada cinco niños en América Latina (32 millones de niños) está en situación de pobreza extrema sobre un total de 81 millones de pobres. En Chile, la encuesta CASEN 2011 mostró que 307.122 niños y adolescentes entre 6 y 19 años no asistían a la escuela o no habían concluido la escolaridad obligatoria. De ellos, 1/3 daba como causa motivos propios de la experiencia escolar; 155 mil niños menores de 17 años tenían dos o más años de rezago. Una de las causas del fracaso escolar, rezago, sobre edad y abandono escolar temprano es la dificultad lectora, derivada mayoritariamente de carencias ambientales y de malas prácticas pedagógicas en la educación inicial. Es significativo que uno de cada dos estudiantes de sectores de vulnerabilidad social no logre las competencias mínimas de alfabetización (lectura fluida y estratégica), mientras que en sectores socioeconómicamente aventajados uno de cada diez niños no logra tales competencias.

El cambio de mirada debe contemplar tanto un cambio en el concepto de alfabetización como una ampliación del concepto de pobreza en la infancia. Un niño es pobre no solo en términos de ingresos de su familia, acceso a salud y adecuada nutrición, sino también en cuanto a desigualdad, inequidad, exclusión, carencia de experiencias y oportunidades enriquecedoras, inexperiencia en los cuidados tanto parentales como de personal de las guarderías, lo que deriva en negligencia afectiva, ausencia de estimulación cognitiva de calidad y el cada vez más frecuente flagelo del maltrato. Todos estos factores provocan un impacto acumulativo sobre el potencial cognitivo y socioafectivo del niño; este impacto es transgeneracional.

Las desigualdades, inequidad y exclusión afectan también a niños migrantes, refugiados, solicitantes de asilo, niños de pueblos originarios. Entre ellos, los hijos de migrantes indocumentados o en situación migratoria irregular se encuentran con barreras de acceso y marginación mucho más críticas en términos de oportunidades, siendo estas barreras extraordinariamente críticas en niños migrantes y solicitantes de asilo con 
discapacidades. Los desafíos que surgen de la condición de migrantes y/o de niños provenientes de pueblos indígenas y tribales para llevar a cabo una alfabetización exitosa son considerables. Es preciso contemplar los factores inherentes a la condición bilingüe, transformándolos de barreras a fortalezas de alfabetización. Para ello, los niños deben contar con adultos dispuestos a llevar a cabo una alfabetización en el contexto de una pertinencia cultural respetuosa, con material apropiado y con una adecuada motivación. Diversos estudios muestran que los niños hijos de migrantes se muestran más dispuestos a una correcta alfabetización precisamente cuando cuentan con educadores respetuosos de su cultura. En EEUU, adolescentes hijos y/o nietos de migrantes llevan a cabo fructíferos intercambios culturales con sus familias, a través de movilizar su dominio de tecnologías, para asistir a sus padres y abuelos en el ingreso a redes comunicacionales con sus comunidades de origen, mientras que los padres y abuelos les conectan con las tradiciones, la lengua y las lecturas de sus comunidades y países de origen (W.S. Eva Lam, 2012).

\section{INFANCIA, LECTURA Y TECNOLOGÍAS DIGITALES}

Escribir sobre infancia y lectura en la era de las tecnologías digitales posee para algunos un sospechoso aroma a naftalina. Cada día aumenta el contingente de adultos que estiman anacrónico el énfasis colocado sobre la competencia lectora tradicional —lectura de material impreso, especialmente libros - en una era que transita aceleradamente hacia el conocimiento a través de los medios digitales. Contra este movimiento se alza la voz de quienes se niegan a leer una novela en un Kindle, nostálgicos del suave fru fru de las hojas de papel, del olor a estanterías olvidadas, de la posibilidad de leer con un lápiz en la mano que vaya amarrando suavemente los momentos de emoción a la memoria. Suele ocurrir que las transiciones históricas provoquen debates apasionados, induzcan a las polarizaciones extremas y faciliten afirmaciones del tipo "nunca", olvidando que nunca hay que decir nunca. Las tecnologías digitales marcan de modo indeleble la coexistencia de dos generaciones: la de los nativos digitales, formada por quienes nacieron inmersos en el mundo digital (los nacidos desde los 80 en adelante, pero muy especialmente los nacidos en este siglo, llamados "millenials") y la de los inmigrantes o visitantes digitales, que alcanzaron la adultez durante el siglo XX. Ambas generaciones se diferencian por sus cerebros y sus mentes, radicalmente diferentes (G. Small, 2010).

Sobre el cableado básico de soporte proporcionado por el ADN se va configurando en el niño de este siglo un cerebro nuevo, cuyas diferencias con el cerebro de sus padres y de sus abuelos será mayor en la medida en que haya sido más tempranamente expuesto de modo cotidiano a la experiencia de una pantalla digital (un teléfono móvil, una tablet, una consola de videojuegos, un computador... o todas ellas de modo simultáneo). Las investigaciones coinciden en mostrar que la exposición temprana y cotidiana a los medios digitales modela un cerebro capaz de focalizar la atención de modo simultáneo sobre más de una variable; que la atención es atraída por estímulos visuales dinámicos (en movimiento) que se suceden velozmente o que ocurren de manera simultánea en un 
espacio determinado; que la habilidad lógica espacial y el procesamiento holístico se desarrollan muy tempranamente en desmedro de la lógica simbólica y del procesamiento secuencial, y que las regiones encargadas de la cognición social experimentan un menor desarrollo. Como consecuencia, la mente digital privilegia la atención múltiple y veloz, procesa la información de manera global en desmedro del procesamiento analítico, desestima lo secuencial privilegiando lo holístico y es menos hábil en el registro visual de un contexto social, empleando con menor frecuencia la mirada como código comunicativo y mostrándose menos competente en destrezas interaccionales tales como la mentalización, la proxémica y la pragmática (la capacidad de elaborar teorías acerca de lo que el otro piensa, el uso del espacio como relación con otros y adecuación de la conducta al contexto). Como contrapartida, el cerebro analógico o predigital tiende a privilegiar la atención focal sostenida sobre un estímulo, colocando el resto en un segundo plano (por ejemplo, se focaliza sobre un texto, ignorando lo que ocurre en la pantalla de la TV, o viceversa); analiza, centrándose en lo conceptual y en lo icónico por separado para luego realizar una tarea de síntesis. Sabe elegir entre procesos convergentes y divergentes según el objetivo y es considerablemente más hábil en emplear los recursos de cognición social para interactuar con otros. Son dos mentes diferentes, que surgen de dos cerebros igualmente distintos. No hay cerebros ni mentes más evolucionados ni más aventajados ni más sofisticados que otros. Sus fortalezas y debilidades se ponen en evidencia frente a una tarea específica. Por ejemplo, si se trata de elegir un buen cirujano laparoscópico, probablemente un cerebro fuertemente digital será el que ofrezca las mayores garantías de éxito quirúrgico. Pero si se trata de elegir a un editor literario, un cerebro predigital que hace gala de dar origen a una mente lectora experta sobrepasará en habilidades a un experto en informática. Cabe preguntarse, en este escenario nuevo que hoy domina el mundo occidental, si la condición de experto en tecnologías digitales favorece una mayor experticia en lectura en el caso de un adolescente que disfruta tanto un buen libro como un buen videojuego, y si la condición de lector experto favorece la realización de actividades a través de medios digitales. Hay evidencias respecto a la segunda situación. Se ha demostrado que un lector experto lleva a cabo búsquedas por Internet mucho más eficientes que un mal lector. Seleccionan fuentes confiables llevando a cabo análisis críticos más sofisticados, evalúan de mejor modo la credibilidad del sitio y son mucho más flexibles respecto a continuar en dicho sitio o abandonarlo para buscar otras fuentes. En otras palabras, hacen gala de una competencia crítica y creativa similar a la que emplean cuando leen, incrementando la eficacia de su trabajo.

Basta dar un paseo por la ciudad para darse cuenta de que la vida cotidiana va a la retaguardia de los avances tecnológicos, y que el libro es todavía un heroico sobreviviente. Todavía existen los kioscos de periódicos, semanarios y revistas varias; todavía es posible hallar bibliotecas públicas en los barrios, gente que lee en los escaños de las plazas —no solo ancianos jubilados... también más de algún joven o niño—; todavía se organizan con relativo éxito ferias del libro, jornadas y encuentros literarios, ventas de libros usados. Todavía existe el oficio de escritor, el IVA aplicado a los libros todavía implica ganancias para el Estado. Y aún existen aquellos que prefieren regalar un libro a sus hijos en lugar de un smartphone. Todas estas evidencias permiten afirmar que libro 
y lectura son un patrimonio vivo que se niega a ingresar al pasado sin retorno. Por ello, todavía es tiempo para que ayudemos a los niños a realizar una transición más suave hacia el mundo de la tecnología cibernética. Toda la comunidad debe participar en una campaña espontánea en pro de mantener vivo en los niños y niñas el interés por la lectura temprana y gozosa. Las familias deben intentar poner límites de tiempo a la entretención digital, dando el ejemplo a la hora de leer por placer; deben reflexionar antes de correr a adquirir el último modelo de tablet o de teléfono móvil. Se debe llevar a cabo una revisión profunda del concepto de alfabetización que hoy impera en el sistema educativo chileno, un concepto por lo demás bastante miope y estrecho. Se debe seleccionar de modo riguroso la calidad de los escritores infantiles y juveniles, así como la calidad de los ilustradores. Los gobiernos regionales y el Estado deben colocar toda su energía en promover condiciones de igualdad y equidad en el acceso pleno de los niños a la alfabetización. Y cada chileno debe saber convertir las situaciones cotidianas en experiencias lectoras de calidad, porque detrás de todo niño lector experto hay adultos que le abrieron amplia la puerta de ingreso a la magia de la lectura desde el ejemplo. Solo desde esta defensa viva del libro y la lectura podremos dar respuesta a la lúcida interrogante de Ángela Pradelli:

" ¿Es exagerado pensar que nuestras vidas dependen en alguna medida de nuestras lecturas? ¿Que el destino de nuestras horas está ligado a los textos que fueron conformando en nosotros una visión del mundo en un arco que se traza entre el desasosiego y el entusiasmo?".

\section{BIBLIOGRAFÍA}

"La pobreza infantil: un desafío prioritario", en revista Desafíos N 10, 2010.

Borzone de Manrique, A.M., Leer y escribir a los cinco, Buenos Aires: Aique, 2009, 248 pp.

Eva Lam, W.S., Warriner, D.S., Transnationalism and Literacy: investigating the mobility of people, languages, texts and practices in the contexts of migration, Reading Research Quarterly, 47 (2), 2012, págs. 191-215.

Kuhl, P.K., Early language learning and literacy: neuroscience implications for education, Mind Brain Educ 5 (3), 2011, págs. 128-142.

Pradelli, A., El sentido de la lectura, Buenos Aires: Paidós, 2013, 235 pp.

Schiefele, U., Schafnner, E, Möller, J., Wigfield, A., Dimensions of reading motivation and their relation to reading behavior and competence, Reading Research Quarterly, 47 (4), 2012, págs. 427-463.

Small, G., Vorgan, G., El cerebro digital, Barcelona: Urano, 2009.

Wolf, M., Cómo aprendemos a leer, Buenos Aires: Ediciones B, 2008, 335 pp. 